\title{
Development of Reading Comprehension Skills among the Students of Learning Disabilities
}

\author{
Mohamad Ahmad Saleem Khasawneh,", Mohamad Omar Abu Al-Rub² \\ ${ }^{1}$ Department of Special Education, King Khalid University, Saudi Arabia \\ ${ }^{2}$ Faculty of Arts and Educational Sciences, Ajloun University, Jordan
}

Received July 14, 2020; Revised August 25, 2020; Accepted September 17, 2020

\section{Cite This Paper in the following Citation Styles}

(a): [1] Mohamad Ahmad Saleem Khasawneh, Mohamad Omar Abu Al-Rub, "Development of Reading Comprehension Skills among the Students of Learning Disabilities, "Universal Journal of Educational Research, Vol. 8, No. 11, pp. 5335 - 5341, 2020. DOI: 10.13189/ujer.2020.081135.

(b): Mohamad Ahmad Saleem Khasawneh, Mohamad Omar Abu Al-Rub (2020). Development of Reading Comprehension Skills among the Students of Learning Disabilities. Universal Journal of Educational Research, 8(11), 5335 - 5341. DOI: 10.13189/ujer.2020.081135.

Copyright $\odot 2020$ by authors, all rights reserved. Authors agree that this article remains permanently open access under the terms of the Creative Commons Attribution License 4.0 International License

\begin{abstract}
The objective of this study was to investigate the impact of a training program based on the visual words composition techniques on the development of reading comprehension skills. The sample of the study consisted of (104) learning disabilities pupils. A questionnaire that was developed by the researcher was used as a measuring instrument. The results indicated that there were statistically significant differences between the mean of performance of the experimental and the control groups in the reading comprehension skills development posttest in favor of the experimental group that was taught using the training program based on the visual words composition techniques. Students with learning disabilities in the current study were given organized and ordered learning tasks and assignments as the instructional program was based on visual picture techniques in presenting the targeted words. Also, the instructional program included well-defined and achievable objectives, learning activities, teaching tools and instruments, and evaluation tools taking into consideration students' ability levels and had the same effect on students from both genders. The study concludes that visual words composition techniques should be integrated with the Arabic language curriculum to develop the language skills among students with learning disabilities generalization of findings is highly related to the size of the study sample.
\end{abstract}

Keywords Visual Words, Reading Comprehension Skills, Learning Disabilities

\section{Introduction}

Reading is a psychological mental process that entails the ability to transform written symbols into verbal symbols. It is one of the basic psychological activities requiring the use of various mental processes to be employed in various contexts. It is also one of the basic skills in the cognitive dimension of child development, a major focus of teaching and learning in the early school stages, a significant means for acquiring knowledge. The reading skill represents the third level of the hierarchical model for language development containing five levels: Receptive language, expressive language, reading, writing, and employing written and verbal language in daily life (Al-Khasawneh, 2020).

Reading comprehension is one of the most important reading skills and is important to achieve the main objectives of the whole reading process. Reading comprehension has become a major characteristic of good readers who can be a significant contributor to the development of society. It is an activity requiring accuracy, autonomy while reading, deep understanding, comprehension speed, enjoying reading, the variation in reading purposes, being involved with the different events, giving opinions, being critical, and creative.

To facilitate reading, and to facilitate reading 
comprehension, children should be trained to identify and recognize words learned to the level where he/ she can visually recognize them. Visual words are common words the reader can recognize at the first glance without the need for analyzing them to the syllabus of sounds they constitute Children unable to form many visual words will never be a good reader, will have a limited capacity in combining words in basic thinking units to reach reading fluency and comprehension. Furthermore, he/ she will face serious problems in recognizing new or uncommon words for him (Khasawneh \& Al Khawaldeh, 2018).

It can be noticed, then, that comprehension is the basic component of reading. Without comprehension, reading cannot be described as a mental process. Reading comprehension is not an innate ability as it is not an easy facilitated skill ending when the reader can recognize the written symbols and say them. Indeed, it is a complex process falling in variant levels, requires mental abilities and potentials, needs practice and drill, and the use of different thinking, explanation, analysis, critique, and contrasting skills.

The significance of the study stems from the special attention educational systems pay for developing students' reading skills to improve their reading comprehension. The current study can be described as one of the new studies examining the effect of visual word formulation on reading comprehension(Khasawneh, M. 2020).

While reviewing related previous literature, Casalis, Quemart, and Duncan ${ }^{3}$ examined the effect of language at the derived grammar use in the visual words and children's words' processing and found that some of the morphological grammar children possess may facilitate children's words recognition, limit their ability to recognize inaccurate words in both English and French. The results of the study also indicated statistically significant differences in the words' morphological processing level due to language, in favor of French compared to English. In another study, Francis, Camacho, and Lara ${ }^{4}$ studied levels of frequency in the translated words from Spanish to English and from English to Arabic and their effect on single-word comprehension. The results of the study found an effect for word frequency levels on reading comprehension, that the presentation of repeated words within various reading and writing language contexts had more effect on reading comprehension compared to single words presentation.

$\mathrm{Yi}$ et al. ${ }^{5}$ investigated the potential mechanisms causing reading disorders among a sample of dyslexia students. The results of the study indicated that the visual domain in the left brain hemisphere was not able to activate the visual recognition functions for the presented words to students. In another study, Abdelhaleem, Naser, LutfAllah, and $\mathrm{Al}$ Dughiadi $^{6}$ examined the effect of a Mazarano Model-based blended electronic instruction program on improving pictures reading skills among preparatory stage students with learning disabilities. The results of the study found statistically significant differences between students' means scores on the pictures reading skills test (recognition, description, analysis, synthesis, meaning inference), in favor of experimental group students compared to controls.

Abdelnabi ${ }^{7}$ studied the effect of picture reading based teaching strategy on developing creative writing among $5^{\text {th }}$-grade students. The results of the study indicated that there were statistically significant differences between students' means scores on the creative writing pre-posttests, in favor of posttest; confirming the effectiveness of picture reading based teaching strategy on developing creative writing among $5^{\text {th }}$-grade students.

Al Zoubi and Al Hamadani ${ }^{8}$ sought to identify visual recognition speed for Arabic letters in light of their forms, the number of points on each letter, location of points in each letter, and the location on each letter online, and whether they are linked with other letters or being segregated from letters. The results of letters points indicated that students reported more speed in visually recognizing letters without points compared to letters with points. The results of the study showed differences in visual recognition speed for the letter with two points compared to one point and three-point letters. The results also found that letters with lower points were more visually recognized by students compared to letters with upper points. Results relating to the linkage or the segregation of the letter, letter location on writing lines showed that students reported higher speed levels in segregated letters recognition compared to link one, the letters were written upper and lower the line were more recognized compared to letters online.

Hassan $^{9}$ investigated the effect if reciprocal teaching based programs on secondary school students' reading comprehension achievement level. The results of the study showed statistically significant differences in students' reading comprehension achievement tests, in favor of the experimental group students taught using the reciprocal teaching program. On the other hand, Al Qatawneh ${ }^{10}$ examined the effect of a generative teaching instructional program on developing reading comprehension and awareness levels for English reading among Jordanian secondary stage students. The study indicated that there were substantial differences in the reading comprehension total test and on the literal, inferential, and critical levels, in favor of the experimental group students taught using the generative teaching model.

After reviewing Arabic and foreign educational studies investigating the use of visual words formulation techniques and their role in reading comprehension skills development among students, the researcher noticed:

- There is paucity in previous studies targeting visual word formulation techniques.

- Several studies showed low reading comprehension levels among students. This low level was attributed to several reasons such as traditional reading instruction methods common in schools, the weak reading curricula, and the absence of listening skill instruction. 
The current study attempted to integrate the visual words formulation techniques in Arabic curricula for students with learning disabilities in Abha Region to develop their skills in reading comprehension. To the researcher's limited knowledge, this is one of the first studies integrating visual word formulation techniques in Arabic in the Abha region.

\section{Questions of the Study}

The study addressed the following questions:

1. What is the effect of visual words formulation techniques based instructional program on the development of reading comprehension skills among students with learning disabilities at Abha Region?

2. Is there an interaction between visual words formulation techniques based instructional program and gender on the development of reading comprehension skills among students with learning disabilities at the Abha Region?

\section{Significance of the Study}

The significance of the study stems from the enormous attention the school pays to promote reading skills among students with learning disabilities, particularly their reading comprehension competence. The current study can be described as one of the latest studies in the field that examines the effect of visual word formulation skills on reading comprehension. The significance of the study can be noticed in the following:

- The current study provides a teaching guide employing visual picture technologies and this may help teachers address the weaknesses found in students with learning disabilities acquisition of reading comprehension skills.

- The current study is based on the assumptions of educational reform requirements calling the need for the use of new technologies and software to be tools for promoting students with learning disabilities competences and abilities.

- The current study provides Arabic curriculum developers an opportunity to employ visual word formulation technologies and implement them in teaching Arabic.

\section{Definitions of Terms}

- The Teaching Program: A combination of instructional drills and strategies based on the employment of visual words formulation technologies, which consisted of linking the written word technique, linking the verbal word technique, word recognition strategy instruction, word squares technique instruction.

- Students with Learning Disabilities: Students showing disorder in one or more of the basic psychological processes entailing understanding and employing written and verbal words, and affects hearing ability in the form of auditory disorders, thinking, speech, reading, spelling, and mathematics. This disorder can be linked with some brain functional disorder and is not related with any form of disability, whether mental, visual, hearing impairment, or other11. In this study, students with learning disabilities are diagnosed using the standard test acknowledged by the educational district at Hayel Region as a diagnosis tool for learning disabilities.

- Reading Comprehension: A mental process where the student interacts with the written text using their previous experiences in recognizing the reading text content, explaining, and evaluating it. In this study, reading comprehension was measured using the reading comprehension test developed by the researcher to measure three levels of reading comprehension: literal, inferential, and critical among students with learning disabilities at the Abha Region.

- Visual Words: These are the most common words that are frequently employed and recognized by children at night without the need for word analysis to a sequence of sound syllabus comprising this word (Khasawaneh, M., \& Arabia, 2016).

\section{Limitations of the Study}

The study sample was confined to learning disabilities students in the $3^{\text {rd }}, 4^{\text {th }}, 5^{\text {th }}, 6$ th grades, aged 8-11 years enrolling in the schools at Abha Region educational district in the second semester of the school year 2016//2017.

\section{Methods and Procedures}

\section{Sample of the Study}

The subjects of the study were $3^{\text {rd }}, 4^{\text {th }}, 5^{\text {th }}, 6^{\text {th }}$ basic stage graders enrolled at the resource-rooms in the schools affiliated to the Abha educational district in the first semester of the school year 2015/2016.

Table (1) shows the distribution of the sample according to their gender and teaching method

Table 1. The distribution of the sample according to their gender and teaching method

\begin{tabular}{|c|c|c|c|}
\hline \multirow{2}{*}{ Group } & \multicolumn{2}{|c|}{ Gender } & \multirow{2}{*}{ Total } \\
\cline { 2 - 3 } & Male & Female & \\
\hline Experimental & 26 & 26 & 52 \\
\hline Control & 26 & 26 & 52 \\
\hline Total & 52 & 52 & 104 \\
\hline
\end{tabular}

\section{Instruments of the Study}

To achieve the objectives of the study, the following instruments were employed: An achievement test 
measuring reading comprehension among students with learning disabilities, the suggested instructional program based on the visual words formulation techniques suggested to improve reading comprehension skills.

\section{First Instrument: Reading Comprehension Achievement Test}

The researcher developed the reading comprehension achievement test based on a thorough review of related literature to identify the differences between the pretest/posttest performance of students with learning disabilities to develop their reading comprehension skills. In the development of the achievement test, the researcher employed a list of reading comprehension skills based on a review of related previous literature. The achievement reading comprehension test consisted of (30) items, as (10) of these items measure one of the reading comprehension levels (literal, inferential, and critical). The main objective of the achievement test was to measure the subjects' achievement and mastery of reading comprehension skills before the implementation of the instructional program. The reading comprehension skills list was the key to the development of the achievement test items

\section{The validity of the Achievement Test}

The achievement test was given in the preliminary format before implementation to experts of faculty members as they were asked to give their opinions about the items of the achievement test in terms of the following:

1. Content validity.

2. The ability of the items to measure reading comprehension skills that should be mastered by learning disability students.

3. Language structure and item clarity.

The experts agreed that the items of the achievement test were written according to students' writing expression levels, appropriate for learning disabilities students concerning their abilities and skills. But, they recommended the need for unifying the pre- posttests items as there was some variance in items between the two achievement tests. The content validity of the achievement test was $(90 \%)$ noting that the researcher considered the remarks of the experts to increase the content.

\section{Difficulty and Discrimination}

Difficulty and discrimination coefficients for the test items were calculated as shown in table (2).
Table 2. Difficulty and discrimination coefficients for the test items

\begin{tabular}{|c|c|c|}
\hline Item & Difficulty & Discrimination \\
\hline 1 & 0.667 & 0.667 \\
\hline 2 & 0.548 & 0.556 \\
\hline 3 & 0.563 & 0.556 \\
\hline 4 & 0.667 & 0.444 \\
\hline 5 & 0.618 & 0.444 \\
\hline 6 & 0.686 & 0.556 \\
\hline 7 & 0.639 & 0.667 \\
\hline 8 & 0.676 & 0.556 \\
\hline 9 & 0.816 & 0.444 \\
\hline 10 & 0.692 & 0.556 \\
\hline 11 & 0.550 & 0.667 \\
\hline 12 & 0.634 & 0.444 \\
\hline 13 & 0.833 & 0.667 \\
\hline 14 & 0.674 & 0.778 \\
\hline 15 & 0.591 & 0.556 \\
\hline 16 & 0.711 & 0.556 \\
\hline 17 & 0.783 & 0.444 \\
\hline 18 & 0.766 & 0.444 \\
\hline 19 & 0.667 & 0.778 \\
\hline 20 & 0.673 & 0.333 \\
\hline 21 & 0.780 & 0.556 \\
\hline 22 & 0.824 & 0.333 \\
\hline 23 & 0.654 & 0.556 \\
\hline 24 & 0.755 & 0.889 \\
\hline 25 & 0.796 & 0.556 \\
\hline 26 & 0.836 & 0.778 \\
\hline 27 & 0.804 & 0.556 \\
\hline 28 & 0.825 & 0.667 \\
\hline 29 & 0.759 & 0.556 \\
\hline 30 & 0.831 & 0.778 \\
\hline
\end{tabular}

As seen in Table (2), item discrimination coefficients ranged between (0.333-0.889) and all of these values are acceptable, indicating that the discriminative ability of these items was adequate. This statistical procedure measures item characteristics, its discriminative ability between examinees from high and low levels. The item reporting an average of (0.30) discrimination coefficient value is acceptable.

The difficulty coefficients values were between $(0.548)$ and (0.836) and all of these values are acceptable as the item is accepted if reporting a difficulty coefficient ranging between $(0.150)$ and $(0.850)$. 


\section{Reliability of the Achievement Test}

To check the reliability of the achievement test, Cronbach alpha, and split-half reliability for the test items were calculated as seen in Table (3).

Table 3. Cronbach alpha and split-half reliability for the test items

\begin{tabular}{|c|c|}
\hline Cronbach alpha coefficient & Split half coefficient \\
\hline 0.825 & 0.895 \\
\hline
\end{tabular}

Table (3) shows that Cronbach alpha and split-half reliability coefficients values were high and this ensures high-reliability levels.

\section{Second Instrument: The proposed training program for developing reading comprehension skills}

\section{The objectives of the program}

The program aims to develop reading comprehension skills among students with learning disabilities and to achieve the following:

1. Develop expression and reading comprehension skills among elementary stage students with learning disabilities.

2. Increase the achievement levels in reading comprehension skills among students with learning disabilities.

\section{The conceptual framework for the program}

The starting point for the development of this model is the low reading comprehension skills among average students in the elementary stage in general, and students with learning disabilities in particular. There is also a need for developing programs that can promote reading comprehension skills among this student population. The current model is based on the following rationales:

- Students report low reading comprehension levels in the different school stags in general and among students with learning disabilities in particular. This was documented in several previous studies examining students reading comprehension level in Arabic, the results of reported studies in Arabic indicating that students report low achievement levels in Arabic skills acquisition.

- The information developments and the changes in the Saudi society dictate the need for developing performance in Arabic teaching so Arabic becomes a viable and developed language in the minds and hearts of society members.

- Reading comprehension skills are not limited to only Arabic as student's comprehension ability is the key to success in other school subjects and low levels of this ability may mean failing other school subjects.

\section{Program implementation}

The researcher implemented the program on the students in the experimental group at King Abdel Aziz Elementary School at Abha. The program contained (30) sessions, each lasting for (25) minutes during the first chapter of the school year 2015/2016.

\section{Results of the Study}

To answer the first and second questions of the study, means and standard deviations of the two study groups' performance on reading comprehension pre-posttests the performance in light of the instructional program and gender. Table (4) shows this.

As seen in Table (4), there were substantial differences in the means scores of the two study groups in the reading comprehension pre-posttests in light of the instructional program and gender. To identify the significance of the differences between the means scores of the two groups in light of instructional program and gender at the significance level $(\alpha \leq 0.05)$, Two way ANCOVA analysis was employed. The results of the Two way ANCOVA are shown in table (5).

Table 4. Means and standard deviations for the two study groups performance on the reading comprehension pre-posttests performance in light of the instructional program and gender

\begin{tabular}{|c|c|c|c|c|c|c|}
\hline \multirow{2}{*}{ Program } & \multirow{2}{*}{ Gender } & \multirow{2}{*}{ N. } & \multicolumn{2}{|c|}{$\begin{array}{c}\text { Language reading comprehension } \\
\text { skills pretest } \\
\end{array}$} & \multicolumn{2}{|c|}{$\begin{array}{c}\text { Language reading comprehension } \\
\text { skills posttest }\end{array}$} \\
\hline & & & $\mathrm{M}^{*}$ & SD & $\mathrm{M}^{*}$ & SD \\
\hline \multirow{3}{*}{ Language instruction } & Male & 26 & 11.77 & 2.566 & 25.75 & 2.219 \\
\hline & Female & 26 & 12.23 & 3.253 & 25.71 & 2.920 \\
\hline & Total & 52 & 12.00 & 2.910 & 25.73 & 2.568 \\
\hline \multirow{3}{*}{ Control } & Male & 26 & 11.85 & 2.796 & 19.23 & 2.471 \\
\hline & Female & 26 & 12.81 & 2.800 & 18.62 & 2.351 \\
\hline & Total & 52 & 12.33 & 2.813 & 18.92 & 2.408 \\
\hline
\end{tabular}

$*$ Maximum grade $=30$. 
Table 5. Two way ANCOVA for the study groups performance on reading comprehension pretest in light of instructional program and gender

\begin{tabular}{|c|c|c|c|c|c|}
\hline Source of variance & Total squares & $\begin{array}{c}\text { Degrees of } \\
\text { freedom }\end{array}$ & Total squares average & $F$ value & Sig. \\
\hline Reading comprehension pretest & 19.040 & 1 & 19.040 & 3.100 & 0.081 \\
\hline instructional program & 1183.391 & 1 & 1183.391 & 192.703 & 0.000 \\
\hline Gender & 1.017 & 1 & 1.017 & 0.166 & 0.685 \\
\hline Program*gender & 1.886 & 1 & 1.886 & 0.307 & 0.581 \\
\hline Error & 607.960 & 99 & 6.141 & & \\
\hline Total & 53680.000 & 104 & & &
\end{tabular}

Table (5) shows that $\boldsymbol{F}$ value for the instructional program was (192.703), with a significance level of (0.000); indicating that there was a statistically significant difference between the means scores of the two study groups' performance on the reading comprehension achievement posttest. This means that the first null hypothesis stating:" there is no statistically significant differences at the significance level $(\alpha \leq 0.05)$ between the means scores of students with learning disabilities grades on the reading comprehension skills at Abha Region due to the instructional program (language instructional program, traditional instructional program) is rejected.

Moreover, table (5) shows that the $\boldsymbol{F}$ value for the interaction between the instructional program and gender was (0.307), with a significance level of (0.581); indicating that there was no difference in the effect of the instructional program due to gender. This proves the second null hypothesis, which states that there are no statistically significant differences at the significance level $(\alpha \leq 0.05)$ between the means scores of reading comprehension skills development level among students with learning disabilities due to the interaction between the instructional program and gender. The modified means were calculated as shown in table (6).

Table 6. Modified means and standard deviations for the two study groups performance on the reading comprehension skills test due to the instructional program and gender

\begin{tabular}{|c|c|c|c|c|}
\hline Program & gender & N. & $\begin{array}{c}\text { Modified } \\
\text { Means* }\end{array}$ & Standard error \\
\hline \multirow{3}{*}{$\begin{array}{c}\text { Language } \\
\text { program }\end{array}$} & Male & 26 & 25.67 & 0.487 \\
\cline { 2 - 5 } & Female & 26 & 25.74 & 0.486 \\
\cline { 2 - 5 } & Total & 52 & 25.71 & 0.486 \\
\hline \multirow{3}{*}{ Traditional } & Male & 26 & 19.18 & 0.487 \\
\cline { 2 - 5 } & Female & 26 & 18.71 & 0.489 \\
\cline { 2 - 5 } & Total & 52 & 18.95 & 0.488 \\
\hline
\end{tabular}

*Maximum grade $=30$.

It can be seen from the previous table that the modified means scores for the experimental group taught using the language instructional program was $(\mathrm{M}=25.71)$, and this value is higher than the one reported among control group students as the modified means scores for this group was $(M=18.95)$. This indicates that the difference between the two study groups was in favor of the experimental group using the language instructional program in the reading comprehension skills development.

\section{Discussion}

The results of the current study may be explained from the fact that the instructional program developed based on the visual words formulation techniques motivated students with learning disabilities when they encountered a new instructional method respecting their abilities, affirming their self-concept and the need for their interaction while working on the assigned learning task. This led to higher self-confidence when engaging in the learning task. Moreover, the new methods employed in the instructional process, addressing the problems from different and various perspectives resulted in broaden students' horizons and helping them regulate their information in new ways different from the traditional thinking styles. Students were able to formulate visual pictures for words, use them in promoting their reading abilities, and adopt various alternative solutions.

The current study results are consistent with the findings reported in the studies of Casalis, Quemart, and Duncan, Francis, Camacho, and Lara, Abdelhaleem, Nasr LutfAllah, and Dhogaidi, Abdelnabi and Al Hamadani, Hasan ${ }^{12}$, and Al-Qatawneh.

The fact that there was no interaction between the instructional program and gender can be explained from various perspectives. The instructional program took into consideration the students' learning styles and their development level. The presented reading texts and exercises conformed to their cognitive experiences and backgrounds; the reading content was very close to students' and appropriate to their age group. Also, the use of visual pictures techniques in presenting the words may have played a role in motivating students, encouraging them to engage in the learning tasks. It was also a driver for students for more effort and progress.

Students with learning disabilities in the current study were given organized and ordered learning tasks and assignments as the instructional program was based on visual picture techniques in presenting the targeted words. Also, the instructional program included well-defined and achievable objectives, learning activities, teaching tools 
and instruments, and evaluation tools taking into consideration students' ability levels and had the same effect on students from both genders.

\section{Recommendations}

In light of the results found in the current study, the following recommendations were developed:

- $\quad$ To employ the instructional language program based on visual picture techniques in presenting words in teaching students with learning disabilities at Abha Region reading comprehension skills.

- Train teachers to use the instructional language program based on visual picture techniques in teaching students with learning disabilities.

- To capitalize on the developed reading comprehension skills list proposed in the current study.

\section{Conclusions}

The study concludes that visual words composition techniques should be integrated with the Arabic language curriculum to develop the language skills among students with learning disabilities generalization of findings is highly related to the size of the study sample. The present study is limited to students with learning difficulties. The selected student's age ranges from (8-11) years and no other ages have been selected. The sample of this study is limited to students, who enrolled in the rooms of learning difficulties of schools that belong to the Department of Education in the Assir Region.

\section{Acknowledgments}

The author would like to express their gratitude to Kink Khalid University, Saudi Arabia for providing administrative and technical support.

\section{REFERENCES}

[1] Abdelhaleem, R, Naser, M, Lutfallah N, Aldhogaidi, H. A Mazarano. (2013). Model-based blended electronic learning program to develop pictures reading skills among preparatory stage students with learning disabilities. Journal of Faculty of Education. 25(1): 73-99.

[2] Abdelnabi, S. A pictures reading based proposed reading strategy for developing some creative writing skills among $5^{\text {th }}$ basic stage graders (2012). Educational Studies Institute, Cairo University: Egypt.

[3] Al Khasawneh, M. Developmental learning disabilities. Dar
Al Fiker Publications: Amman, 2015.

[4] Al-Qatawneh, Khalil. (2005). The Effect of The Generative Teaching Model on Jordanian Secondary School Students Reading Comprehension and Strategy Awareness in English. Unpublished doctoral dissertation, University of Amman Arab University for Graduate Studies: Jordan.

[5] Alwaqfi, R. (2012).Learning disabilities: Theory and Practice. Dar Al Maseera for Printing and Distribution: Amman.

[6] Alzoubi, A, Alhamdani, M. (2007).Arabic language letters visual recognition speed based on the characteristics for their perceptual patterns: An experimental study. Journal of Educational Sciences. 12: 43-72.

[7] Casalis, S., Quemart, P, Duncan, L. (2015). How language affects children's use of derivational morphology in visual word and pseudoword processing: Evidence from a cross-language study. Frontiers in Psychology. 6(452): 1-11.

[8] Francis, W, Camacho, A, Lara, C. (2014) Words translated in sentence contexts produce repetition priming in visual word comprehension and spoken word production. Mem Cogn. 42: 1143-1154.

[9] Hasan, N. (2006).The Impact of A reciprocal Teaching Strategy on Enhancing the Jordanian Secondary Stage Students Reading Comprehension in English. Unpublished doctoral dissertation, University of Amman Arab University for Graduate Studies: Jordan.

[10] Hasan, Nadia. (2006). The Impact of A reciprocal Teaching Strategy on Enhancing the Jordanian Secondary Stage Students Reading Comprehension in English. Unpublished doctoral dissertation, University of Amman Arab University for Graduate Studies: Jordan.

[11] Jad, M. The effectiveness of a proposed instructional strategy in developing some reading comprehension skills among second preparatory stage students. Journal of Reading\& Knowledge. 2013; 16: 17-50.

[12] Khasawaneh, M., \& Arabia, S. (2016). The Impact of a Training Program Based on the Visual Words Composition Techniques on the Development of Reading Comprehension Skills among the Students of Primary Stage. Advances in Bioresearch, 7(2).

[13] Khasawneh, M. A. (2020). Constructing A Training Programmed and Measuring its Effects on Improving Cognitive Skills' Enhancement among Learning Disability Students.IUG Journal of Education and Psychology Science. Vol. 28, No. 1.

[14] Khasawneh, M. A., Al Ahmad, F. A., \& Al Khawaldeh, M. A. (2018). The Effects of Training Program based on Auditory Perception Skills in Enhancing Phonological Awareness among Learning Disability Students in the Aseer Region. Journal of Educational and Psychological Studies [JEPS], 12(3), 591-604. https://www.iasj.net/iasj?func=arti cle\&aId $=154301$

[15] Yi, W, Wu, T, Chen, W, Yuan, T, Luo, B, Shan, C. (2014). Lefthemiparalexia of Chinese characters; Neglect dyslexia or disruption of the pathway of visual word form processing?. Brain Struct Funct. 219: 283-29. 